\title{
Topical Preparation
}

National Cancer Institute

\section{Source}

National Cancer Institute. Topical Preparation. NCI Thesaurus. Code C29639.

Natural or synthetic compounds or mixtures that are applied to body surfaces such as the skin, mouth, vagina, lips, nose, ears or the eyes. A topical preparation can act only on the specific area to which it is applied or it can be applied locally to be absorbed into the blood stream and act systemically. 